\title{
On creation of the universal mathematical management decision making theory
}

\author{
Victoria Kondratenko \\ V.M.Glushkov Institute of Cybernetics of NAS of Ukraine \\ Glushkov avenue 40, Kyiv, Ukraine, 03187 \\ science.and.life@gmail.com, orcid.org/0000-0003-1577-6701 \\ Received on 18.04.2019, accepted after revision for publication on 12.05.2019 \\ https://doi.org/10.31493/uwt1909.1201
}

\begin{abstract}
A variety of approaches to the construction of theories of managerial decisionmaking causes great difficulties in constructing formal models of the dynamic processes under study, which necessitates the creation of a unified universal mathematical theory of managerial decision-making. The model of managerial decision making for dynamic systems of any nature proposed by the author uses the axiomatic modeling methodology created earlier, combining the axiomatic method and the concept of functional analysis in modeling and solving problems - one of the extremely effective tools for cognizing patterns in natural processes.

The aim of this work is to demonstrate the simplicity and capabilities of the proposed methodology for making managerial decisions on a specific example in the field of medicine. The truth (correctness, expediency) of making a managerial decision is proved by the exact mathematical method, which assumes a formal proof that does not depend on the will of a particular person. This circumstance, as well as the universality of the model, determines the relevance and originality of the proposed approach to solving managerial problems. The formal proof of the truth of the obtained solution by the Robinson method and the use of the author's universal stereotypical logical construction for proving theorems is the key to the maximum degree of confidence in the obtained solution.

Despite the verbal format for formulating axioms, the solution obtained is not approximate, not probabilistic, but mathematically accurate, which is extremely important for the practical application of mathematical theory. The format under consideration for formulating basic axioms and theorems
\end{abstract}

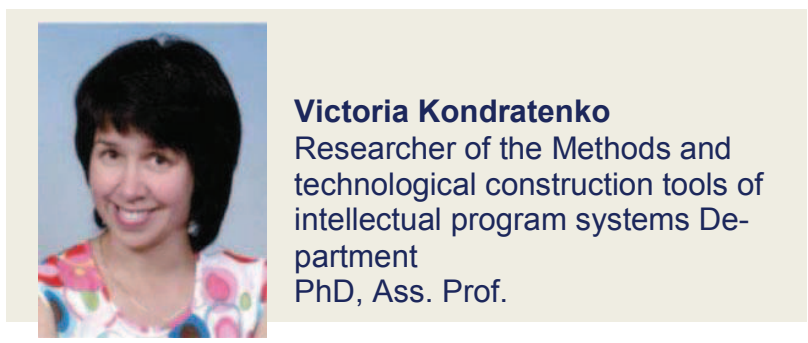

requiring proof is convenient for human perception and reasoning. It is easily applicable in solving problems in any field of human activity by specialists of the most diverse subject areas of human activity. The prospectivity and cost-effectiveness of the proposed approach is especially relevant in solving extremely complex practical problems.

Keywords: axiomatic modeling, artificial intelligence, mathematical logic, thinking, formalization.

\section{INTRODUCTION}

Relevance of a subject. Decision theory, like any other scientific theory, performs both cognitive and predictive functions in relation to the observed natural or man-made phenomena.

The cognitive function [2] consists in the study and formal description of all physical variables and their parameters, which functionally fully and unambiguously characterize all the permissible states of the studied natural or man-made phenomena, as well as the laws of all interactions and relationships between 
the mentioned state variables during their (phenomena) of normal life.

The predictive function, with the specified functionality of the cognitive function, is to enable:

- firstly, the automatic identification of scientifically based reasons for deviations in the dynamics of the observed phenomenon from normative indicators;

- secondly, the automatic formation of an algorithm to eliminate the identified causes that caused a violation of the normative course of the observed phenomenon.

Naturally, any decision theory with the mentioned functionality should be provided with a mathematical model [3] capable of covering this functionality.

The purpose of the study is to create the necessary logical-dialectical model for each theory of decision making, to consider the essence of its semantic content.

It is well known that the main goals of constructing theories of natural phenomena vital activity [4] are:

- visual format reflection, identified through field experimentation a list of physical variables revealed by field experimentation that is functionally complete and unambiguous, characterizing all the permissible states (static, stationary, and dynamic) of the natural phenomenon being studied during its life;

- relationships revealed by field experimentation and their laws between the variables characterizing each of the states in this phenomenon;

- established by natural experimentation of the natural laws of life of the investigated natural phenomena.

- replacement of full-scale experimentation with computational experimentation (in the volume of reflection of a functionally complete scenario of the cognizable physical or physiological phenomenon activity) based on the constructed theory concepts when predicting the evolution of the natural phenomenon under study [3].

If it is impossible to doubt the feasibility of achieving the first goal for an objective reason - no memory, the knowledge is simply not feasible $[5,6]$, then the feasibility of achieving the second goal is far from obvious for the following reasons:

- both philosophers of science and natural scientists and mathematicians do not have convincing and incontrovertible, necessarily formally provable, logical statements that make it possible, in a purely theoretical way, without involving the results of a field experiment, to establish the truth [7]:

- as the scientific thinking itself, so the truth of the final "conjunction - conclusion" causal relationship as a whole with a functionally complete discussion with a logical consequence of the dialectic of the vital activity of the natural phenomenon under study.

Together they could attest to the fact of the correct, formal logical deduction of the conclusion from the premises under conditions of unknown truth of the meaning of the conclusion itself. And the fact of derivability itself would be a proof of the expediency of achieving the second goal.

But the philosophers of science are well aware of:

- That, firstly, any hypothetical theorizing as part of the natural phenomena activity theories is not only unacceptable, but also harmful [8].

- That, secondly, all the widely applicable in classical mathematics for the purpose of proving the truth of thinking with substantive proof of theorems, the five stereotyped tautologies, including the "modus ponens" tautology, are by definition incorrect [9].

- That, thirdly, to invent correct tautologies without the results of a full-scale experiment by definition is not possible, because of the secondary thinking with respect to matter.

- That, fourthly, matter and everything material is primary in relation to consciousness and thinking, and therefore, an exclusively natural experiment establishes the truth of even the most professional thinking.

It is for these reasons that philosophers of science do not recognize a purely theoretical substantive proof of theorems, without its confirmation by historical practice.

In order to free oneself from doubts on the validity of the philosophers of science position when cognizing new natural phenomena, it 
suffices to recall the scientific definitions of cognitive scientists [10] assigned to such concepts as "higher mental functions", their subset consisting of at least 22 elements, and called "intellectual functions", and those that are part of the latter, such concepts as "consciousness" and "thinking".

\section{Higher mental functions (HMF)}

Specific human mental processes, which are the processes of movement, manipulation, processing, protection, retrieval and destruction of information in neural networks of the central nervous system [4], which is associated with:

- knowledge of the human environment;

- development of tactics and strategies for safe human behavior in the environment;

- knowledge of natural and man-made phenomena of the universe;

- implementation of 22 intellectual functions;

- implementation of 9 gnostic functions;

- implementation of a single amnestic function;

- implementation of central nervous system management by all subsystems of the autonomic nervous system;

- and, possibly, with the implementation of many other functions that are still unknown to humanity.

Consciousness is the highest form of information reflection about the material environment of a person in the substrate of natural neural networks of the central nervous system (CNS) of this person.

Reflection is a combination of mental processes, which are internal information processes (movement, manipulation, processing, protection, retrieval and destruction of information), allowing a person to:

- navigate this environment, both in time and in space;

- evaluate personal role function in the environment;

- accumulate experience in the environment safe behavior;
- learn the laws of the life of the environment and plan personal behavior in the environment;

- accumulate knowledge about the natural laws of the development of the living environment, in order to continuously improve its well-being in the environment and to ensure its continuous progressive intellectual development, as a person, in the environment.

Thinking is the highest mental function [11, 12] (internal information process), consisting in an indirect, generalized and abstract reflection of the surrounding reality in its essential connections, properties and relationships.

In accordance with the functionality of any of the higher mental functions and, especially, based on the functionality of consciousness, thinking, imagination and recognition of familiar sensory images, as a stereotype of a figurative idea of HMF, as an internal information process one can offer a computer information system (CIS), provided by an associative search and a knowledge base filled with information blocks about natural and man-made phenomena that this particular person has ever met. CIS by all means provides viewing of the information block selected from the knowledge base in the mode declared by the owner of the central nervous system.

All the HMF characteristics presented just now do not in any way give us the reason to represent them as the processes of vital activity of a special kind of matter in the universe, even if this matter would possess the phenomenon of owning knowledge about the state of the matter which it characterizes.

On the contrary, all mental processes in consciousness are purely informational processes, awakening exclusively new informational processes in the central nervous system that control one or another association, one or another imagination, one or another process of thinking, or one or another CNS reflex reaction.

Coming back to the steadfastness of the philosophers of science in assessing the truth of the obtained new scientific knowledge, which (assessment) is based solely on a fullscale experiment, or historical practice with the matter under study, their assessment 
should again and again be supported, since no indirect information (for example, from consciousness, or from any other HMF) about the state of the analyzed matter has the right to exist, as inaccurate information, in comparison with the analytical data on the state of this matter received directly from field experimentation with this matter [11].

In accordance with the above mentioned, the following adequate conclusions suggest themselves.

1. Theories are needed, but exclusively, as an ordered and systematized memory of natural laws and their integrity, which regulate and control the life of a known natural phenomenon. In these theories no hypothetical liberties are permissible, since they inevitably destroy the goals of computational experimentation without its confirmation by historical practice.

2. The evolution prognostication of natural phenomena under study on the basis of hypothetical theories and without the results of field experiments is not permissible - it can result in hard errors.

3. In accordance with the inevitability of full-scale experimentation in predicting the evolution of the phenomena under study, the creation of hypothetical theories designed to implement computational experimentation (in the volume of reflection of a functionally complete scenario of the life activity of a knowable physical or physiological phenomenon), it becomes an absolutely pointless activity, contrary to common sense and the accepted concept of proving the truth of the causal relationship "conjunction of premises - conclusion" based on the results of field experimentation.

The answer to the question at what stage should cognition be completed and, accordingly, the formation of the theory of vital activity of the phenomenon under study, can be formulated as follows - as soon as the answer to the last question of all the goals of cognition is received, provided that each answer is framed in the format of the corresponding theorem proof, formulated and proved with the help of the grammatical resources of the formal logic language of the first-order predicate serving the theory of automatic proof of theorems.
Why should the answers to questions of the cognition goals be necessarily drawn up in the format of the corresponding theorems proof $[12,13]$, and why should the theorems be formulated and proved with the help of the grammatical resources of the formal logic language of first-order predicate serving the theory of automatic proof of theorems [14]?

The answers are utterly simple.

Firstly, for the proof of the truth of thinking with logical statements on any of the topics discussed, there simply does not exist any different format for reflecting the truth of the discussing parties, except for the format for proving theorems.

Secondly, formal evidence is unanimously recognized by all science philosophers as the only format for an objective judgment on the truth of this or that logical statement. This format exclusively provides not only the inheritance of previously obtained scientific knowledge, but also the strict, in the scientific sense, truth of target statements. It is this format that can ensure literacy and security from unreasonable hypotheses of managerial decisions made.

Third, modern science reasonably requires natural scientists to reflect the known natural laws of the life of all living things exclusively in a mathematical format [18, 20-22]. Since this format provides an aphoristic (when the meaning of one formula is equivalent to the meaning of a verbal text, reflected at least on 350 pages), the style of presentation of new scientific knowledge [11, 15, 16], and stimulates self-control of adequacy, correctness, reliability and truthfulness (if any formal theoretical proof) of new knowledge.

Fourth, the theory of automatic proof of theorems declares its own methodology for the proof of theorems, which has minimal laboriousness even using a "manual" proof of these theorems, in comparison with any substantial proof of theorems.

To conclude, let us give a description of the logical-dialectical model that provides the full requirements of any task on the topic of decision-making, which has been tested on hundreds of tasks [3] relating, of course, not only to the topic of decision-making. The need to 
create such a model is formed by an almost century-old aggravating crisis of fundamental science.

By the logical-dialectic model (LDM) of the process of the investigated phenomenon (system) of living Nature functioning is meant [17]:

- a set of physical variables that functionally fully characterizes every dynamic state of this system (phenomenon) that is acceptable by Nature;

- all identified in the process of full-scale experimentation, logical relationships in the phenomenon, i.e. causal relationships and interactions between state variables, expressed exclusively with the help of logical operations, and uniquely identifying each of the observed states of a dynamic system (phenomenon);

- logical relationships between state variables that explore the truth in thinking about a particular phenomenon, and are reflected in a formulaic form;

- all dialectic relations between state variables revealed during the field experiment, reflecting:

1) the nature of the driving forces in the phenomenon, providing the current life of the observed phenomenon, under the conditions of unity and inconsistency, both in the behavioral essence of each elementary object in a phenomenon (considered in LMD as an operand, i.e. a state variable loaded with the meaning of an identifier of a certain physical quantity, accompanied by properties and characteristics of this quantity), and in essence relations between pairwise interacting elementary objects in this phenomenon;

2) the unity and inconsistency of the behavioral essence of each individual elementary object when it functions in a specific phenomenon, in a specific time and space;

3) unity and inconsistency of the essence of the relationship between pairwise interacting elementary objects in the phenomenon;

4) the progressive evolution of the observed phenomenon, in the presence of unity and inconsistency, both in the behavioral essence of each elementary object in this phenomenon, and in the essence of the relationship between pairwise interacting elementary objects in this phenomenon;

5) the progressive evolution of the observed phenomenon in all the variety of its forms and in all its inconsistency;

6) as well as the dialectic relations between state variables in the phenomenon under study are also reflected in the formula form.

The concept of "the nature of the driving forces" provides, first of all, the answer to the question: why is the observed natural phenomenon carried out just like this, and not differently?

\section{EXAMPLE}

\section{Diagnosis and treatment of the pathology of myocardial infarction [23]}

Symptoms, in aggregate, anticipating a person about the occurrence of myocardial infarction:

The pain in the back thorax is so intense that it practically "paralyzes" the patient's will. There is a feeling of impending death. This thorax pain does not disappear after the cessation of physical activity and often spreads (irradiates) to the shoulder and arm (more often to the left), neck, and jaw. Pain may be either constant or intermittent. In time to understand what happened, and immediately call an ambulance (the best way - specialized cardiological one) and take all possible actions in the current situation, means to increase your chance of staying alive not only in the coming minutes, hours and days, but also months, years.

Except for back thorax pain, myocardial infarction can be characterized by the following symptoms and signs:

- Frequent shallow breathing

- Rapid irregular heartbeat

- Rapid and weak pulse on the limbs

- Fainting (syncope) or loss of consciousness

- Feeling of weakness, may be very apparent

- Profuse, sticky, cold sweating

- Nausea and even vomiting

- Pale skin 
Despite the fact that these symptoms and signs allow in most cases to recognize myocardial infarction on time, each of them and even their combinations can also be found in other diseases. But since a heart attack is a life-threatening condition, it is better to play it safe and immediately seek emergency medical care than to regret (you or your relatives) about the forever lost opportunity to avoid fatal consequences. Prior to the arrival of emergency care, you should try to help yourself by putting an ordinary (500 mg) aspirin tablet under your tongue. You can use nitroglycerin, but only if you are sure that blood pressure is not reduced. When the ambulance arrives, the remaining aspirin tablets should be washed off with a glass of water.

Medical practice shows that, unfortunately, in almost $25 \%$ of patients, myocardial infarction can be asymptomatic, the so-called "mute ischemia", or "mute heart attack." But the absence of symptoms, alas, does not exclude damage to the heart muscle. And since there is no "alarm", the patient remains unaware of the developing catastrophe, which negatively affects the prognosis for his life.

\section{Diagnostic tests carried out in the cardi- ac rehabilitation department:}

- ECG, ECHO KG

- Ergospirometry with physical activity (the presence of diseases of the cardiovascular system, the level of physical performance, optimal training modes are determined)

- Laser flowmetry (the state of microcirculation in any area of the skin is determined)

- Transdermal $\mathrm{O}_{2}$ and $\mathrm{CO}_{2}$ percentage determination in the blood

- Complete biochemical blood test (27 indicators)

- Computer research methods:

1. hemodynamic study (APS) with the definition of 22 parameters, including stroke volume, vessel diameter, vascular wall elasticity, vascular resistance.

2. the state of the heart study (Cardiovisor) allows you to quickly assess the condition of the myocardium with the preparation of its color portrait, heart rate and the body's ability to regulate it, the state of the autonomic nervous system

3. Allergy testing and determination of the entire spectrum of harmful loads on the body (chemical, pharmacological, geopathogenic, metabolic, etc.) in a non-invasive bioresonance way on the German MORA hardware-software complex.

The main heart diseases: angina pectoris, coronary heart disease (CHD), heart attack, chronic heart failure (CHF). With all these diseases, the muscle cells of the heart lack nutrition for the work that they must constantly do.

The goal of treatment in a hospital with a heart attack is to restore blood flow in a clotted vessel.

Urgent therapeutic measures are aimed at expanding the lumen of a clogged blood vessel and the maximum possible rescue of fibers and cells of the heart muscle. This is the essence of the treatment.

The main medical intervention for treating an acute heart attack is the dissolution of a blood clot (thrombolysis), which is carried out with the help of intravenous drugs. If these drugs begin to enter the body during the first hours after the heart attack onset of signs, they are able to restore passability of the clogged vessel. But the more time passes, the faster the effectiveness of these drugs decreases. Cardiologists determine the first hour since the heart attack development as "Golden Hour", when the effectiveness of treatment is maximum.

Now let's turn to the universal mathematical theory of managerial decision making proposed by the author, in order to reflect the process of diagnosis and treatment of the pathology of myocardial infarction in a mathematical format. To demonstrate the enormous advantages of this format, since it allows not only to verify the truth of thinking with a logical consequence on the topic under study, but also ensures the derivability of the conclusion of the theorem from its premises based on the data obtained in the experiment.

The formation of a mathematical model of the diagnostic process and treatment of myocardial infarction. 
The symptoms, in aggregate, warning a person about the occurrence of a pathology of myocardial infarction, may be called axioms for diagnosing this disease, and we will assign each of the axioms an identifier in the format of mathematical formalism.

Axiom a1: "Intense, contrasting pain behind the sternum irradiating to the shoulder and arm (more often to the left), neck, jaw" we assign the identifier $\mathrm{p} 1(\mathrm{X})$, in which $\mathrm{p} 1$ carries the semantic load reflected in quotation marks, and $\mathrm{X}-$ is a unique identifier for the patient.

Axiom a2: "Frequent shallow breathing" we assign the identifier $\mathrm{p} 2(\mathrm{X})$.

Axiom a4: "Rapid and weak pulse on the extremities" we assign the identifier $\mathrm{p} 4(\mathrm{X})$.

Axiom a5: "Fainting (syncope) or loss of consciousness" we assign the identifier $\mathrm{p} 5(\mathrm{X})$.

Axiom a6: "The feeling of weakness can be very pronounced" we assign the identifier p6(X).

Axiom a7: "Profuse, sticky cold sweat" we assign the identifier $\mathrm{p} 7(\mathrm{X})$.

Axiom a8: "Nausea and even vomiting" we assign the identifier $\mathrm{p} 8(\mathrm{X})$.

Axiom a9: "Pallor of the skin of the face" we assign the identifier $\mathrm{p} 9(\mathrm{X})$.

\section{Diagnostic tests carried out in the cardi- ac rehabilitation department.}

Axiom a10: "ECG and ECHO CG confirms that the patient has myocardial infarction (MI)", the identifier p10(X).

Axiom a11: "Ergospirometry with physical activity confirms that the patient has myocardial infarction (MI)", the identifier p11(X).

Axiom a12: "Laser flowmetry confirms that the patient has MI, the identifier p12(X).

Axiom a13: "A transdermal $\mathrm{O}_{2}$ and $\mathrm{CO}_{2}$ percentage determination in the blood confirms the presence of MI in the patient", the identifier $\mathrm{p} 13(\mathrm{X})$.

Axiom a14: "A complete biochemical blood test (27 indicators) confirms the patient's MI", the identifier p14(X).

Axiom a15: "The study of hemodynamics (APS) with the definition of 22 parameters, including impact volume, vessel diameter, vascular wall elasticity, vascular resistance, confirms the patient's presence of MI", the identifier p15(X).

Axiom a16: "The state of the heart study (Cardiovisor) with an assessment of the myocardial state confirms the patient's MI", the identifier p16(X).

Axiom a17: "Allergotestration and determination of the entire spectrum of harmful loads on the body by a non-invasive bioresonance method (MORA) confirms the patient's MI", the identifier p17(X).

\section{Prescribing treatment based on diagnos- tic data.}

Axiom a18: "The goal of treatment in a hospital with myocardial infarction is to restore blood flow in a thrombus-clogged vessel that nourishes the myocardium, and to save the fibers and cells of the myocardium as much as possible", the identifier $\mathrm{p} 18(\mathrm{X})$.

Axiom a19: "The main medical intervention in the treatment of an acute heart attack is the thrombus (thrombolysis) dissolution, which is carried out using intravenous drugs. If these drugs begin to enter the body during the first hours after the onset of heart attack signs, they are able to restore patency of the clogged vessel. But the more time passes, the faster the effectiveness of these drugs decreases, the identifier p19(X).

Axiom a20: "Being late with medical heart attack treatment for three hours after the onset of the attack makes the use of thrombolytic drugs practically meaningless", the identifier p20(X).

Axiom a21: "Axioms No. 1 - No. 20 together provide the correct diagnosis and the appointment of the correct method for treating myocardial infarction disease", the identifier p21(X).

Based on axioms No. 1 - No. 21, let us write the logical-dialectic model of myocardial infarction diagnosis and treatment.

$$
(\forall \mathrm{X})((\mathrm{p} 1(\mathrm{X}) \Lambda \mathrm{p} 2(\mathrm{X}) \Lambda \mathrm{p} 3(\mathrm{X}) \Lambda \mathrm{p} 4(\mathrm{X}) \Lambda
$$
$\mathrm{p} 5(\mathrm{X}) \Lambda \mathrm{p} 6(\mathrm{X}) \Lambda \mathrm{p} 7(\mathrm{X}) \Lambda \mathrm{p} 8(\mathrm{X}) \Lambda \mathrm{p} 9(\mathrm{X}) \Lambda$ $\mathrm{p} 10(\mathrm{X}) \Lambda \mathrm{p} 11(\mathrm{X}) \Lambda \mathrm{p} 12(\mathrm{X}) \Lambda \mathrm{p} 13(\mathrm{X}) \Lambda$ $\mathrm{p} 14(\mathrm{X}) \Lambda \mathrm{p} 15(\mathrm{X}) \Lambda \mathrm{p} 16(\mathrm{X}) \Lambda \mathrm{p} 17(\mathrm{X}) \Lambda$ $\mathrm{p} 18(\mathrm{X}) \Lambda \mathrm{p} 19(\mathrm{X}) \Lambda \mathrm{p} 20(\mathrm{X})) \Rightarrow \mathrm{p} 21(\mathrm{X}))=>$ $(\exists X)((\mathrm{p} 1(\mathrm{X}) \Lambda \mathrm{p} 2(\mathrm{X}) \Lambda \mathrm{p} 3(\mathrm{X}) \Lambda \mathrm{p} 4(\mathrm{X}) \Lambda$ 
$\mathrm{p} 5(\mathrm{X}) \Lambda \mathrm{p} 6(\mathrm{X}) \Lambda \mathrm{p} 7(\mathrm{X}) \Lambda \mathrm{p} 8(\mathrm{X}) \Lambda \mathrm{p} 9(\mathrm{X}) \Lambda$ $\mathrm{p} 10(\mathrm{X}) \Lambda \mathrm{p} 11(\mathrm{X}) \Lambda \mathrm{p} 12(\mathrm{X}) \Lambda \mathrm{p} 13(\mathrm{X}) \Lambda$ $\mathrm{p} 14(\mathrm{X}) \Lambda \mathrm{p} 15(\mathrm{X}) \Lambda \mathrm{p} 16(\mathrm{X}) \Lambda \mathrm{p} 17(\mathrm{X}) \Lambda$ $\mathrm{p} 18(\mathrm{X}) \Lambda \mathrm{p} 19(\mathrm{X}) \Lambda \mathrm{p} 20(\mathrm{X}))=>\mathrm{p} 21(\mathrm{X}))$

If in the formula [1] the expression:

$(\mathrm{p} 1(\mathrm{X}) \Lambda \mathrm{p} 2(\mathrm{X}) \Lambda \mathrm{p} 3(\mathrm{X}) \Lambda \mathrm{p} 4(\mathrm{X}) \Lambda \mathrm{p} 5(\mathrm{X})$ $\Lambda \mathrm{p} 6(\mathrm{X}) \Lambda \mathrm{p} 7(\mathrm{X}) \Lambda \mathrm{p} 8(\mathrm{X}) \Lambda \mathrm{p} 9(\mathrm{X}) \Lambda \mathrm{p} 10(\mathrm{X})$ $\Lambda \mathrm{p} 11(\mathrm{X}) \Lambda \mathrm{p} 12(\mathrm{X}) \Lambda \mathrm{p} 13(\mathrm{X}) \Lambda \mathrm{p} 14(\mathrm{X}) \Lambda$ $\mathrm{p} 15(\mathrm{X}) \Lambda \mathrm{p} 16(\mathrm{X}) \Lambda \mathrm{p} 17(\mathrm{X}) \Lambda \mathrm{p} 18(\mathrm{X}) \Lambda$ $\mathrm{p} 19(\mathrm{X}) \Lambda \mathrm{p} 20(\mathrm{X}))$

is replaced by the formula $\mathrm{F} 1(\mathrm{X})$, then the formula [1] will take the following form:

$$
\begin{aligned}
& (\forall \mathrm{X})(\mathrm{F} 1(\mathrm{X})=>\mathrm{p} 21(\mathrm{X}))=> \\
& =>(\exists X)(\mathrm{F} 1(\mathrm{X})=>\mathrm{p} 21(\mathrm{X})) .
\end{aligned}
$$

The theory of automatic theorem proving [14], in order to reduce formulas to the canonical format containing only axioms and three logical operations (conjunction, disjunction and negation), 27 formal rules are defined and proven, which describe equivalent transformation of formulas of first order predicate logic.

Two of them look as follows:

$$
\begin{aligned}
& (\mathrm{F} 1(\mathrm{X})=>\mathrm{F} 2(\mathrm{X})) \equiv(\mathrm{IF} 1(\mathrm{X}) \mathrm{V} \mathrm{F} 2(\mathrm{X})) \\
& (\mathrm{F} 1(\mathrm{X})=>\mathrm{F} 2(\mathrm{X})) \equiv\left(\mathrm{F} 1(\mathrm{X}) \Lambda^{\prime} \mathrm{IF} 2(\mathrm{X})\right)
\end{aligned}
$$

One of the rules determines

$$
\text { ' } \mathrm{I} \equiv \forall .
$$

One prescribes freeing the formula of all generality quantifiers if it doesn't contain any other quantifiers.

If one used four of these last rules, formula (2) on the first step becomes

$$
\begin{gathered}
(\forall X)(\operatorname{IF} 1(X) \vee p 21(X))=> \\
(\exists X)(\operatorname{IF} 1(X) \vee p 21(X)) .
\end{gathered}
$$

And in the next step (3) is converted to:

$$
\text { (IF1(X) V p21(X)) } \Lambda
$$

$$
\text { I('IF1(X) V p21(X)). }
$$

Formula (4) represents conjunction of only two contrary components.

That demonstrates its discrepancy, but also demonstrates the validity of the theorem in general as the methodology of the automatic proof of theorems is based on a conclusion of discrepancy of a formula of the theorem in general.

Therefore, the theorem is successfully proved.

\section{CONCLUSION}

The proposed universal mathematical model for making managerial decisions based on the methodology used in medical practice for diagnosing and treating certain pathologies of the human body allows us to reflect this methodology in a mathematical format, providing the possibility of proving the feasibility and effectiveness of the treatment of the analyzed pathology. The axiom base is formed by experimenting directly with patients suffering from the analyzed pathology. The mathematical apparatus for making a managerial decision will ensure the maximum compactness of the formulation of the problem and its solution, unambiguity, and guaranteed accuracy of the solution itself, the heritability of the knowledge gained in the studied subject area and other areas of knowledge that affect the solution of the set managerial problem, as well as the very possibility of solving a complex and extremely complex problem.

\section{REFERENCES}

1. Lyalkina G.B., 2012. Mathematical foundations of decision theory. Ed. V.A. Trefilova. Guidance. Perm, Perm Publishing House. Polytechnic University, 118 (in Russian).

2. Kondratenko V.A., 2014. A living matter in an image of formal models (From physiological heredity to intelligence with its assets). The collection of articles of the author, Kiev, Scientific publication of LLC, Yunik Print, 186 (in Russian). 
3. Kondratenko V.A., 2010. Creation of a uniform stereotype of a logical design of thinking for the substantial and formal proof of theorems. Kiev Scientific publication of Alephof, 267 (in Russian).

4. Anokhin P.K., 1998. Chosen works. Cybernetics of functional systems. Moscow, Medicine, 400 (in Russian).

5. Agadzhanyan N.A. Tel L.Z., Tsirkin V.I., Chesnokova S.A., 2003. Human physiology. (The textbook for medical higher education institutions), under the editorship of the academician of the Russian Academy of Medical Science Agadzhanyan and professor N.A. Tsirkin, the Medical book, N. Novgorod, NGMA Publishing house, 408 (in Russian).

6. Kondratenko V.A., 2016. Creation of formal model of standard dialectic logic of automatic control of the a human body anatomic functional systems. The 5th International scientific and technical conference Information Systems and Technologies Kharkiv-Koblevo IST-2016 (on September 12-17, 2016), 8-9 (in Russian).

7. Kondratenko V.A., 2016. Dialectic logic of management of the autonomic nervous system of the person. Computer mathematic, No.1, 125-133 (in Russian).

8. Kondratenko V.A., 2017. Artificial intelligence. A plan and realities of the current time against the background of natural intelligence of the person. Kiev, Scientific publication Zadruga, 84 (in Russian).

9. Kondratenko V.A., 2015. Paradoxes of science of the twentieth century. The twenty first century - dialectic logic against mysticism, Kyiv, Scientific publication Zadruga, 200 (in Russian).

10.Kondratenko V.A., 2016. Mathematical models of physiological processes of metabolism, reflex and intellectual activity head vegetable pulp of the person. Kiev, Scientific publication Zadruga, 128 (in Russian).

11.Kondratenko V.A., 2018. Formal logicaldialectical models of higher mental functions of a person, as the basis of creative scientific thinking. X International Symposium "Actual Problems of Biophysical Medicine", Kyiv Material of the International Symposium 16-18 May 2018, 30 (in Russian).

12.Chen Ch., Li R., 1983. Symbolic Logic and Mechanical Theorem Proving. Chapter 5. Method of resolutions, Mathematical logic and automatic proof of theorem. Academic Press, Moscow, Science, 358 (in Russian).
13. Guts A.K. Chapter, 2003. Method of resolutions, Mathematical logic and theory of algorithms. Omsk, Heritage. Dialogue Siberia, 108 (in Russian).

14.Nilsson N.J., 1982. Principles of artificial intelligence. Springer-Verlag Berlin Heidelberg, 476.

15.Mendelssohn E., 1984. Introduction to mathematical logic, Moscow, Nauka, 320 (in Russian).

16.Russell S., Norvig P., 2009. Artificial intelligence: a modern approach, 3rd ed. Prentice Hall, 1152.

17.Turing A., 1950. Computing Machinery and Intelligence. Mind, Vol. 59, No.236, 433-460.

18. Vladislav Bogdanov, 2017. Impact of a hard cylinder with flat surface on the elastic layer. Underwater Technologies, Vol.05, 8-15.

19.Kondratenko VA, 2011. Quantum physics without the geometrization of physical models of the universe, a priori free of hypothetical and incorrect formalisms. Kiev: Scientific publication "Aleph", 107 (in Russian).

20.Petro Kulikov, Mykhailo Sukach, 2015. About readiness of Ukraine to mastering minerals of world ocean. Underwater Technologies, Vol.02, 3-10 (in Russian).

21.Nikolay Zhuk, Myron Nazarian, Yury Stelmakhov, 2015. Great Silk Road: modern problems of reconstruction. Underwater Technologies, Vol.01, 59-64 (in Russian).

22.Andrey Tevyashev, 2018. Information and analytical technology for optimal management of sustainable development and functioning of water supply systems. New horizon of underwater explorations. Underwater Technologies, Vol. 08, 47-49 (in Russian).

23.Kobylyanu G.N., Grischenkov E.N., Kuznetsov V.I., Mansur T.I., 2017. Emergency cardiological care in general medical practice: a training manual. RUDN, 77 (in Russian).

\section{О создании универсальной математической} теории принятия управленческих решений

\section{Виктория Кондратенко}

Аннотация. Разнообразие подходов к построению теорий принятия управленческих решений вызывает большие трудности при построении формальных моделей исследуемых динамических процессов, что обуславливает необходимость создания единой универсальной математической теории принятия управленче- 
ских решений. Предлагаемая автором модель принятия управленческих решений для динамических систем любой природы использует созданную ею ранее методологию аксиоматического моделирования, совмещающую в себе аксиоматический метод и концепцию функционального анализа при моделировании и решении проблемных задач - один из чрезвычайно эффективных инструментов познания закономерностей в природных процессах.

Целью настоящей работы является демонстрация простоты и возможностей предлагаемой методологии принятия управленческого решения на конкретном примере в области медицины. Истинность (корректность, целесообразность) принятия управленческого решения доказывается точным математическим методом, предполагающим формальное, не зависящее от воли того или иного конкретного человека, доказательство. Это обстоятельство так же, как и универсальность модели, определяют актуальность и оригинальность предлагаемого подхода к решению управленческих задач. Формальное доказательство истинности полу- ченного решения методом Робинсона и использование авторской универсальной стереотипной логической конструкции для доказательства теорем является залогом максимальной степени доверия к полученному решению.

Несмотря на вербальный формат формулирования аксиом, полученное решение является не приближенным, не вероятностным, а математически точным, что чрезвычайно важно для практического применения математической теории. Рассматриваемый формат формулирования базовых аксиом и теорем, требующих доказательства, удобен для восприятия и рассуждений человека. Он легко применим при решении задач в любой сфере деятельности людей специалистами самых разнообразных предметных областей деятельности человека. Перспективность и затратная экономичность предлагаемого подхода особенно актуальна при решении сверхсложных практических задач.

Ключевые слова: аксиоматическое моделирование, искусственный интеллект, математическая логика, мышление, формализация. 